\title{
Tatumella ptyseos Causing Severe Human Infection: Report of the First Two Brazilian Cases
}

\author{
Paulo Sérgio Gonçalves da Costa, Juliana Monteiro de Castro Mendes and Geyza Machado Ribeiro
}

Division of Infectious Diseases of Monte Sinai Hospital \& Suprema Medical School; Juiz de Fora, MG, Brazil

\begin{abstract}
Tatumella ptyseos is the type species of the Tatumella genus (Enterobacteriaceae). This fermentative Gram-negative rod has only rarely been reported as a cause of human infections; there is very little information about it in the medical literature. We report here the first two Brazilian cases of $T$. ptyseos infections, both evolving to severe sepsis. Key-Words: Tatumella ptyseos, sepsis, Brazil.
\end{abstract}

Scientific information about Tatumella species is scarce, as are confirmed human infections; only 10 articles were found in a recent (4/05/2008) Pubmed/Medline search. This agent was first characterized by Hollis in 1981 [1], as belonging to an unclassified bacterial group previously denominated EF-9 and named T. ptyseos (Tatumella from Harvey Tatum a CDC microbiologist, and ptyseos, epithet of sputum, given the large number of isolates from that source) [1]. Its biochemical properties include indole, urease, methyl red, Voges-Proskauer and gelatinase negative and phenilalanine deaminase, sucrose, and catalase positive [1,2]. Differences between T. ptyseos and other Enterobacteriaceae include a large zone of inhibition around penicillin, the tendency to die in blood agar in seven days and the small number of flagella [1,2]. DNA studies have shown Enterobacter agglomerans to be the closest Enterobacteriaceae species, but the homology does not exceed 38\% [1,2]. Biochemical similarities have been observed between T. ptyseos and both E. agglomerans and Chromobacterium violaceum, but the DNA relatedness to the latter is only $2 \%[1,2]$. A tight phylogenetic affiliation between Pantoea and Tatumella was recently demonstrated by partial sequencing of elongation factor Tu gene (tuf) and F-ATPase â sub unit gene $(a t p D)$ [3]. Tatumella ptyseos human infections have been exceedingly rare worldwide, with no previous reports of human infections from Brazilian clinical settings.

\section{Case Reports}

Case 1

In November 2007, a 41-year-old woman was admitted to the Hospital with a clinical picture of intestinal sub occlusion. She reported a gastric reduction surgery two years before; an emergency exploratory laparotomy was performed. After seven days in the ICU, where she was treated with imipenem plus metronidazole, she was discharged to the ward. Two days later she started to have high fever, chills, tremor and hypotension. Blood tests showed leucocytosis, with a shift to the left (16,100-5\% bands) and increased CRP. An intravenous central line with secretions was observed;

Received on 6 May 2008; revised 11 October 2008.

Address for correspondence: Dr. Paulo Sérgio Gonçalves da Costa. Rua Pasteur 164- 1001 - A Zip code: 36015-420 Juiz de Fora, Minas Gerais, Brazil. Phone number 553299879514 - 32175716. Fax number 5532 32322002. E-mail: psgcosta@acessa.com.

The Brazilian Journal of Infectious Diseases

2008;12(5):442-443. (C) 2008 by The Brazilian Journal of Infectious Diseases and Contexto Publishing. All rights reserved. no other obvious source of infection was identified (Normal abdominal CT, chest $\mathrm{X}$ ray and urinanalysis); consequently, a sepsis-associated catheter diagnosis was made. The catheter was sent to culture; it revealed positive for a nonfermentative Gramnegative rod identified by automated Microscan Baxter using a Dade Behring B101.7-119 plate as T. ptyseos ( $>99.9999 \%$ of probability and no second option), showing the following antimicrobial susceptibilities (MIC): amikacin $(<16)$, ampicillin $(>16)$, ampicillin/sulbactam $(<8 / 4)$, ceftazidime $(<2)$, cefazolin $(<4)$, cefepime $(<4)$, cephalothin $(<8)$, ceftriaxone (16), ciprofloxacin $(<0.5)$, cotrimoxazole $(>2 / 38)$, gentamicin $(<1)$, imipenem $(>8)$, ofloxacin $(<1)$, piperacillin (32), piperacillin/tazobactam $(<16)$, ticarcillin/ clavulanate $(<16)$, and tobramycin $(<4)$. She was put on a new antibiotic scheme with ampicillin/sulbactam; after 10 days, she was discharged, completely recovered.

\section{Case 2}

In December 2007, a 74-year-old man was admitted to the hospital with a sudden-onset high fever associated with malaise, myalgias, headache and dyspnea. His axillary temperature was $40^{\circ} \mathrm{C}$, blood pressure $60 / 40 \mathrm{~mm} \mathrm{Hg}$, pulse rate $140 / \mathrm{min}$ and respiratory rate $30 / \mathrm{min}$. He suffered from type II diabetes, controlled with oral drugs. Initial laboratory tests showed leukocytosis with a left shift and a positive CRP. An admission chest $\mathrm{X}$ ray was normal. A diagnosis of severe sepsis was made, and initial antibiotic therapy with ampicillin/sulbactam plus ciprofloxacin started after blood cultures were taken. Given the disease's severity, the patient was transferred to the ICU for hemodynamic control. The patient remained hypotensive for three days and developed an inflammatory edema associated with lymphangytis in the lower right limb (Figure 1A). No evidence of thrombophlebitis or fasciitis was detected by image techniques. Chest $\mathrm{X}$ ray follow up showed an alveolar infiltrate affecting both lungs (Figure 1B). All blood cultures (TSB soy broth) revealed positive for a nonfermentative Gram-negative rod identified by automated MicroScan Baxter using Dade Behring B101.7-119 plate as T. ptyseos ( $>99.9999 \%$ probability and no second option), showing the following antimicrobial susceptibilities (MIC): ampicillin ( $<2)$, ampicillin/sulbactam $(<8$ / 4), amikacin (32), cephalothin ( $<8)$, cefazolin $(<4)$, cefepime $(<4)$, ceftazidime $(<2)$, ceftriaxone $(<8)$, ciprofloxacin $(<0.5)$, cotrimoxazole $(<2 / 38)$, gentamicin $(8)$, imipenem $(<1)$, ofloxacin $(<1)$, piperacillin (32), piperacillin/tazobactam $(<16)$, ticarcillin/ clavulanate $(<16)$, and tobramycin $(8)$. Immune system evaluation showed the following immunoglobulin levels (mg/ 
Figure 1. Right leg cellulitis and lymphangitis (A), and chest X-ray showing bilateral pneumonia (B).

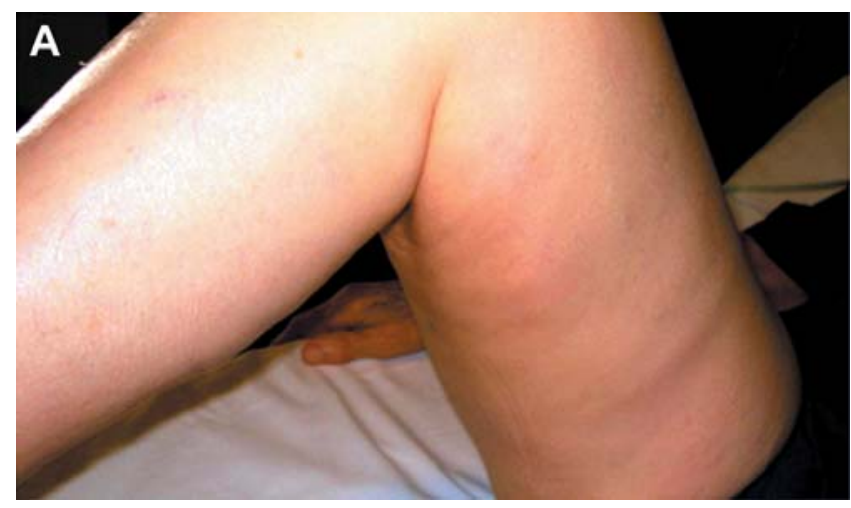

mL): IgG 403, IgA 74, IgM 30, IgE (U) 11. IgG subclass levels (mg/mL) were: IgG 16,310 (2,396-10,835), IgG 2 2,900 (1,2355,487), IgG3202(276-1,344), and IgG41620 (84-888). Complement levels (mg/mL) were C3 103 and C4 16, and CD4 and CD8 counts were $583 / \mathrm{mm}^{3}$ and $74 / \mathrm{mm}^{3}$, respectively. No monoclonal spike was detected in immune electrophoresis.

\section{Discussion}

The T. ptyseos isolates were identified by the Microscan Baxter automated system; though the VITEK automated system has been reportedly ineffective for T. ptyseos identification and antimicrobial susceptibility testing [4], the Microscan Baxter automated system has been considered effective [5].

Clinical information on T. ptyseos infection has been very limited, and isolates from sources other than sputum are uncommon [1,2], with only five cases of blood isolates reported until 2005 [6,7]. Clinical reports associate this agent with tracheobronchial/pulmonary infections (pneumonitis, asthmatic bronchitis, pharyngitis, Wegener granulomatosis, pneumonia, chronic lung disease, and pulmonary edema) $[1,2,4]$, infection associated with pulmonary tuberculosis [8] and gastrointestinal infection (gastroenteritis) [6].

Isolation from other materials, on the other hand, has not been infrequent; this agent has already been found in soil in Brazil [9], vegetation in Japan [10], poultry carcasses in Argentina [11], edible macroalga (Palmaria palmata) in Ireland [12] and water supplies in South Africa [13]. Reported risk factors have been diabetes, older and younger age (neonates) and feeding tubes in neuromuscular disease patients including ataxia telangiectasis patients [1].

These two cases of sepsis, one associated with central venous catheter infection and the other associated with cellulitis, lymphangytis and pneumonia, have no parallel so far in medical literature. The isolate from a central venous catheter was apparently of nosocomial origin and showed previouslyunrecorded resistance to ampicillin and imipenem [1,2,4,5]. The second case isolated from blood resulted from communityacquired disseminated infection and showed negligible antibiotic resistance. The first patient had no known immunodeficiency or risk factor, but the second had diabetes and low IgG3 levels. No DNA testing was made of the T. ptyseos

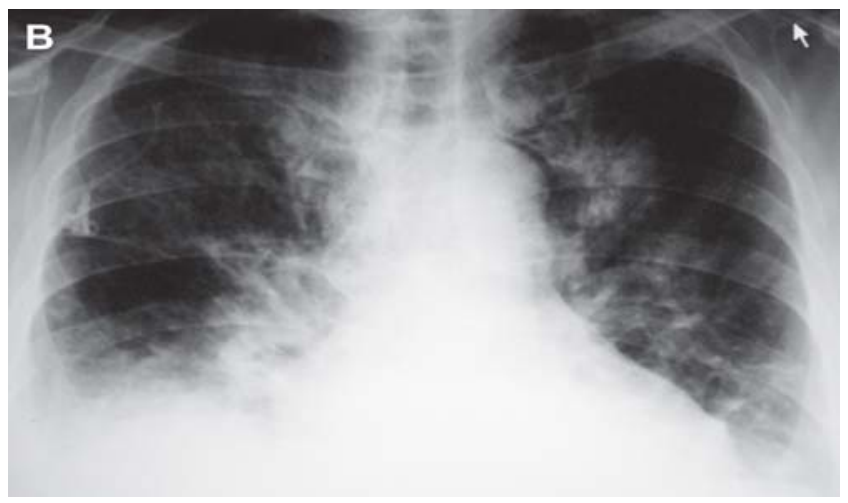

samples, but the different biotypes (data not shown) and different antimicrobial sensitivity patterns suggest no relationship between the two isolates. The identification of two human cases of T. ptyseos infections, one nosocomial and the other community-acquired, should alert microbiologists and medical doctors concerning the potential patogenicity of this agent in different clinical settings in Brazil and elsewhere.

\section{References}

1. Hollis D.G., Hickman F.W., Fanning G.R., et al. Tatumella ptyseos gen. nov., sp. nov., a member of the family Enterobacteriaceae found in clinical specimens. J Clin Microbiol 1981;14:79-88.

2. Farmer III J.J., Davis B.R., Hickman-Brenner F.W., et al. Biochemical identification of new species and biogroups of Enterobacteriaceae isolated from clinical specimens. J Clin Microbiol 1985;21:46-76.

3. Paradis S., Boissinot M., Paquette N., et al. Phylogeny of the Enterobacteriaceae based on genes encoding elongation factor $\mathrm{Tu}$ and F-ATPase subunit. Int J Syst Evol Microbiol 2005;55:2013-25.

4. Stone N.D., O’Hara C.M., Willians P.P., McGowan J.E., Tenover F.C. Comparison of disk diffusion, VITEK 2, and broth microdilution antimicrobial susceptibility results for unusual species of Enterobacteriaceae. J Clin Micriobiol 2007;45:340-6.

5. Rodríguez M.C., Navarrete J.M. Estudio bacteriológico y determinación de La sensibilidad a 21 antibióticos, en uma población de pacientes atendidos en el Hospital General de México durante el año 1999. Enf infec y micro 2001;21:129-44.

6. Janda J.M., Abbot S.L. Uncommon enterobacterial genera associated with clinical specimens. In: The enterobacteria. ASM press 2006:369.

7. Tan S.C., Wong Y.H., Jegathesan M., Chang S.M. The first isolate of Tatumella ptyseos in Malaysia. Malays J Pathol 1989;11:25-7.

8. Berka M., Uzun K., Bozkurt H., et al. Pulmonary infection of Tatumella ptyseos developed on the background of pulmonary tuberculosis. Eastern Journal of Medicine. 2001;6:33-4.

9. Silva V.A., Dias E.S., do Vale R.H.P., et al. Isolamento e identificação de bactérias presentes nos solos de cobertura utilizados no cultivo do cogumelo Agaricus blazei Murril. Ciencia agrotecnica Lavras 2007;31:1364-73.

10. Hiroshi N., Atsuhito E., Norihito T. Browning discoloration by reheating of foods in container-I: Isolation and identification of causal bacteria of browning discoloration of natudaidai. Toyo Junior College of Food Technology and Toyo Institute of Food Technology 2006;26:45-9.

11. Jimenez S.M., Tiburzi M.C., Salsi M.S., et al. The role of visual faecal material as a vehicle for generic Escherichia coli, coliform and other enterobacteria contaminating poultry carcasses during slaughtering. J Appl Microbiol 2003;95:451-6.

12. Moore J.E., Xu J., Millar B.C. Diversity of the microflora of edible macroalga (Palmaria palmate) Food microbiology 2002;19:249-57.

13. Nevondo T.S., Cloete T.E. Bacterial and chemical quality of water supply in the Dertig village settlement. Water SA 1999;25:215-20. 